\title{
Production of Zeolite Sorbents from Burning and Co-burning Biomass with Coal
}

\author{
Michat Łach ${ }^{1}$, Agnieszka Grela ${ }^{2}$ Tomasz Bajda ${ }^{3}$, Dariusz Mierzwiński ${ }^{1,{ }^{*}}$, Norbert Komar ${ }^{4}$, \\ and Janusz Mikuła ${ }^{1}$ \\ ${ }^{1}$ Cracow University of Technology, Faculty of Mechanical Engineering, Institute of Materials \\ Engineering, 37 Jana Pawła II Av., 31-864 Cracow, Poland \\ ${ }^{2}$ Cracow University of Technology, Faculty of Environmental Engineering, Institute of Engineering \\ and Water Management, Warszawska 24, 31-151 Cracow, Poland \\ ${ }^{3}$ AGH University of Science and Technology in Kraków, Faculty of Geology, Geophysics and \\ Environmental Protection, Department of Mineralogy, Petrography and Geochemistry, \\ 30 Mickiewicza Av., 30-059 Cracow, Poland \\ ${ }^{4}$ Ekologia Przedsiębiorczość Innowacje, 17 Kuhna Av., 42-256 Olsztyn
}

\begin{abstract}
The limited resources of natural zeolites make it necessary to search for and use synthetic products. This paper presents a method of producing zeolite sorbents resulting from hydrothermal synthesis in an autoclave. The raw materials used in the syntheses were fluidized-bed fly ashes derived from the burning of forest biomass and sunflower hulls and two fly ashes derived from biomass combustion. The raw materials and zeolite sorbents were characterised using the analysis methods of phase composition and textural properties of the samples. The sorptive capacity of the raw materials and zeolite sorbents was determined by means of cation and anion exchange capacity. The analyses and research have shown that as a result of the synthesis process it is possible to obtain the following zeolite phases: sodalite, faujasite, chabazite. The determined value of the cation and anion exchange capacity for synthetic zeolite sorbents are greater than those which characterise natural zeolites.
\end{abstract}

\section{Introduction}

Increasingly often in the energy sector, renewable energy sources (RES) in the form of solid biofuels are being used. In the national collection (and use) of energy from renewable sources they occupy a dominant position. Their share of the energy from renewable sources in 2015 accounted for $72.22 \%$ of the energy gained from RES [1]. The so-called biomass is incinerated or co-fired with coal or lignite. In the process of such combustion, a fly ash is created with different properties than in the case of coal combustion. Most minerals and phases found in the ashes from the combustion of biomass present in the ashes from the combustion of coal. These include silicates, oxides, hydroxides, sulphates, phosphates, carbonates, chlorides, nitrates, among which silica,

* Corresponding author: dariusz.mierzwinski@mech.pk.edu.pl 
calcite, anhydrite, periclase, and haematite dominate [2-7]. The fly ash from the combustion of biomass shows a significant chlorine and sulphur content [4]. It is therefore necessary to find an application for them that will not pose a threat to the natural environment. Ashes from biomass combustion are among the oldest mineral fertilisers [8]. Fly ash derived from the combustion of biofuels in fluidized bed boilers may be considered as a potential component of adhesives intended for highway use [9], and may also provide a product for the chemical stabilization of sewage sludge [10].

A new direction in the management of ashes from co-combustion and combustion of biomass is the production of zeolite sorbents [11-13]. Due to the high industrial demand for zeolites, methods have been developed for obtaining their synthetic counterparts. In the middle of the last century systematic studies of how to obtain synthetic zeolites were conducted. Initially volcanic ash was used as substrate, and hydrothermal reactions were used at elevated temperatures $\left(50-105^{\circ} \mathrm{C}\right)$ for synthesis. In recent years, the possibilities have been successfully studied of using fly ash from the combustion of coal and lignite for the synthesis of zeolite materials [14-18]. The ability to selectively adsorb pollutants with synthetic zeolites means they are used in many areas, for example, for the removal of organic compounds and heavy metals from contaminated water, as membranes or as molecular sieves. Success in the application of zeolites synthesized from fly ash from the combustion of coal inspired interest in obtaining a new source of synthetic zeolites - fly ash from the combustion and/or co-firing of biomass.

The aim of the study was to obtain synthetic zeolite sorbents from ash from the incineration and co-incineration of biomass. An additional objective was the assessment of raw materials and materials after the methods of phase analysis, textural properties and the value of the cation and anion exchange capacities.

\section{Experiments}

\subsection{Materials}

The raw materials for the production of zeolite sorbents were three types of ash from the incineration and co-incineration of biomass (Fig. 1), whose symbols and description are shown in Table 1.

Table 1. Designations of samples of the materials used in the study.

\begin{tabular}{|c|c|}
\hline Sample & Description \\
\hline AA.0.1 & $\begin{array}{c}\text { Fly ash fluidized bed "Green Block", forest + sunflower } \\
\text { biomass }\end{array}$ \\
\hline AA. $0.1 \mathrm{~A}$ & Sample AA.0.1 after synthesis in the autoclave \\
\hline AA.0.3 & $\begin{array}{l}\text { Fly ash from co-burning, } 5 \% \text { of the biomass including } 20 \% \\
\text { chips }+80 \% \text { straw }\end{array}$ \\
\hline AA. $0.3 \mathrm{~A}$ & Sample AA. 0.3 after synthesis in the autoclave \\
\hline AA.0.4 & $\begin{array}{c}\text { Fly ash from co-burning, } 20 \% \text { of the biomass including } 20 \% \\
\text { chips, } 80 \% \text { sunflower + straw }\end{array}$ \\
\hline AA. $0.4 \mathrm{~A}$ & Sample AA.0.4 after synthesis in the autoclave \\
\hline
\end{tabular}



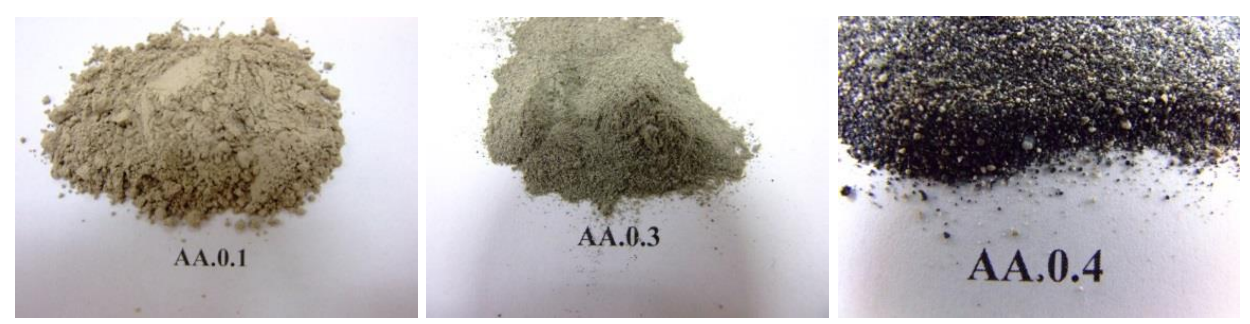

Fig. 1. Photographs of the ash samples tested.

\subsection{Syntheses in autoclave}

The process was carried out in a PARR pressurised chemical reactor (autoclave). The postprocessing waste from the thermal conversion of the waste denoted as AA.0.1, AA.0.3 and AA.0.4 was charged into the reactor, then $2 \mathrm{M} \mathrm{NaOH}$ solution was added to an amount of $1000 \mathrm{ml}$ per $250 \mathrm{~g}$ of waste. The mixture thus prepared was closed in the chemical reactor, in which the pressure was increased up to a level of $0.5 \mathrm{MPa}$. Next, after 5 minutes, the mixture was heated up to $140^{\circ} \mathrm{C}$ at a rate of $2^{\circ} \mathrm{C} / \mathrm{min}$, while the working pressure in the reactor was concurrently raised. The heating time at the reaction temperature was equal to $6 \mathrm{~h}$, and the working pressure was $1.1 \mathrm{MPa}$. After heating, the reaction system was cooled down at a rate of $0.3^{\circ} \mathrm{C} / \mathrm{min}$. The total processing time was $24 \mathrm{~h}$.

Afterwards, the $\mathrm{NaOH}$ solution used for the synthesis was removed (by decanting the liquid from above the sediment) into an appropriate container. The obtained reaction mixture was placed in a vessel with water warmed up to $30^{\circ} \mathrm{C}$. To wash the mixture, a POLSONIC ultrasonic washer was employed. The washing was carried out for $30 \mathrm{~min}$. After the washings were poured out, the reaction mixture was washed with water until the $\mathrm{pH}$ of the washings fell below 9. Next, the reaction mixture was dried at a temperature of $100^{\circ} \mathrm{C}$ for $12 \mathrm{~h}$.

\subsection{Examination methods}

The morphology of samples was studied with a JEOL JSM-820 scanning microscope. Samples were appropriately prepared beforehand. Small quantities of materials were dried to constant mass, and next they were placed on a carbon substrate that ensures removing the charge from the sample. The materials were coated with a thin layer of gold by a JEOL JEE-4X Vacuum Evaporator.

The phase composition of samples before and after synthesis were determined using the powder X-ray diffraction Debye-Scherrer-Hull method. Diffractograms of all samples were recorded using a Rigaku SmartLab X-ray diffractometer and the following parameters: $\mathrm{CuK} \alpha$ radiation, a graphite reflection monochromator, tube voltage $45 \mathrm{kV}$, tube current 200, step scan mode: step size $=0.05^{\circ} 2 \theta$, per $1 \mathrm{~s}$. The values of interplanar distances were used for the identification of phases present in the samples based on data contained in the ICDD (International Centre for Diffraction Data 2014) Catalogue and XRAYAN software.

The specific surface area and porosity were determined from $\mathrm{N}_{2}$ gas adsorption/desorption isotherms at $77 \mathrm{~K}$ using an ASAP 2420 apparatus (Micromeritics). The samples were outgassed for $24 \mathrm{~h}$ at $378 \mathrm{~K}$. The BET equation was used for the specific surface area calculations $\left(\mathrm{S}_{\mathrm{BET}}\right)$.

Cation Exchange Capacity (CEC) was determined with the $\mathrm{NH}_{4}$ sorption-desorption method. Anion Exchange Capacity (AEC) was determined with the phosphate method [19]. 


\section{Results and discussion}

Among the mineral components of the initial ash sample AA.0.1 quartz, feldspar and minerals from the mik group dominate (Fig. 2a). They are accompanied by small amounts of hematite and dolomite.

Sample AA.0.3 has a different composition from AA.0.1. Its dominants were amorphous phase and mullite (Fig. 2b), next to which small amounts of quartz and feldspar appeared. The mineral composition of sample AA.0.4 is dominated by mullite, quartz and amorphous substance (Fig. 2c). Feldspars occur in trace amounts.
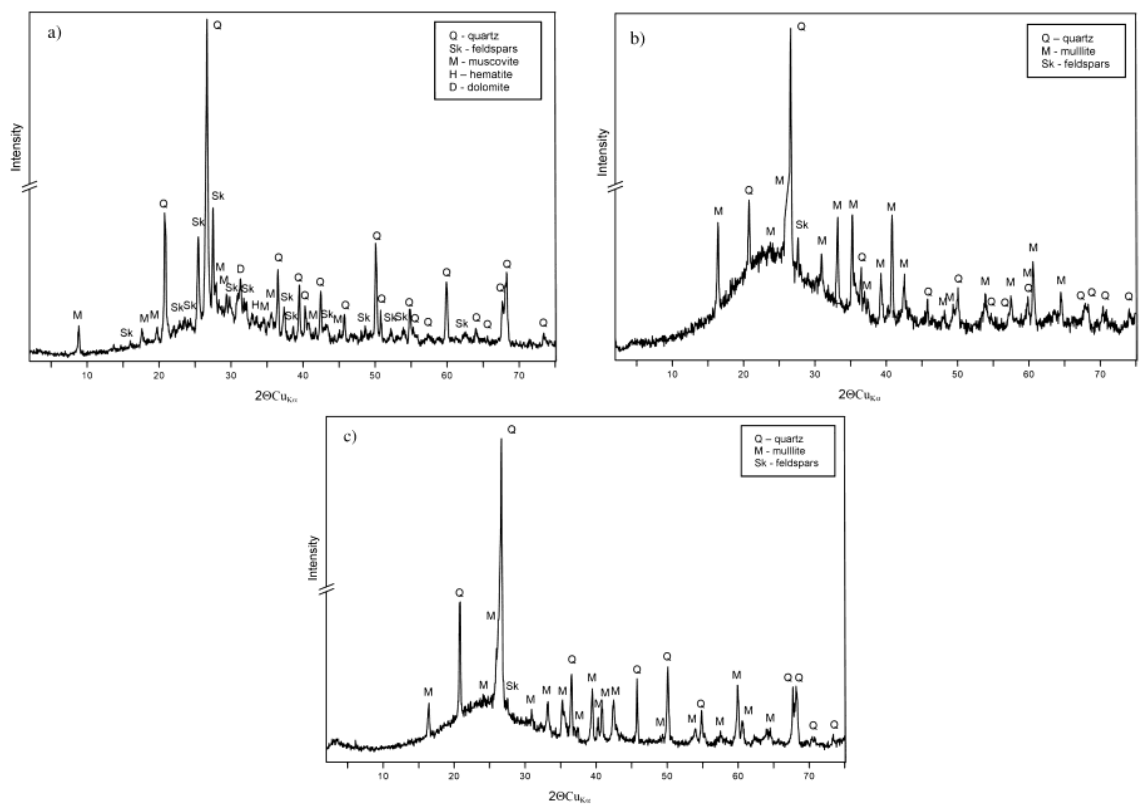

Fig. 2. X-ray diffraction pattern of samples: AA.0.1 (a), AA.0.3 (b), AA.0.4 (c).

XRD analysis allowed the identification of all test samples after synthesis (AA.0.1A; AA.0.3A; AA.0.4A) of the following phases: sodalite, faujasite and quartz (Fig. 3). In samples AA.0.1A and AA.0.4A feldspars were additionally identified (Fig. 3a and 3c). Samples AA.0.3A and AA.0.4A additionally contained mullite (Fig. 3a and 3c).

Between individual samples there were differences in phase composition (in sample AA.0.1A were tobermorite and muscovite identified (Fig. 3a) and in sample AA.0.3A chabazite occurred (Fig. 3b). On the other hand, only in sample AA.0.4A were aqueous sodium hydrogen phosphate, and talc identified (Fig. 3c). The group of zeolites include sodalite, faujasite, and chabazite.

In figures $4 \mathrm{a}, \mathrm{b}, \mathrm{e}, \mathrm{f}, \mathrm{i}, \mathrm{j}$ microphotographs of the samples prior to fusion of ash are shown. In figures $4 \mathrm{c}, \mathrm{d}, \mathrm{g}, \mathrm{h}, \mathrm{k}, 1$ photomicrographs of the samples after synthesis in an autoclave are presented. There is a clear change in morphological forms of the materials in comparison with the starting materials. Materials before treatment had a plate-like $(a, b)$ or spherical $(e, f, i, j)$ shape. The materials after synthesis were characterized by shapes similar to alternately stacked plates or agglomerated rods (c, d) or also present in spherical forms as growths on the surface of the particles of unreacted or polygonal pyramids $(\mathrm{g}, \mathrm{h}, \mathrm{k}, \mathrm{l})$. 

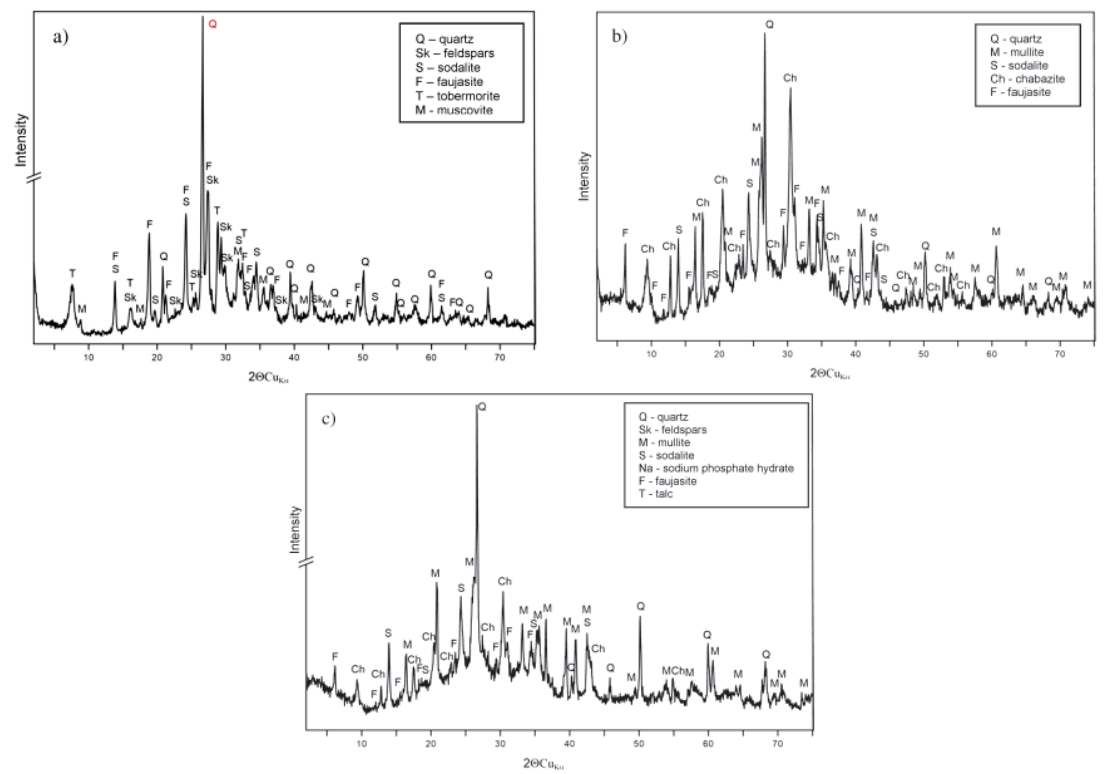

Fig. 3. X-ray diffraction pattern of samples: AA.0.1 A (a) AA.0.3A (b) AA.0.4A (c).
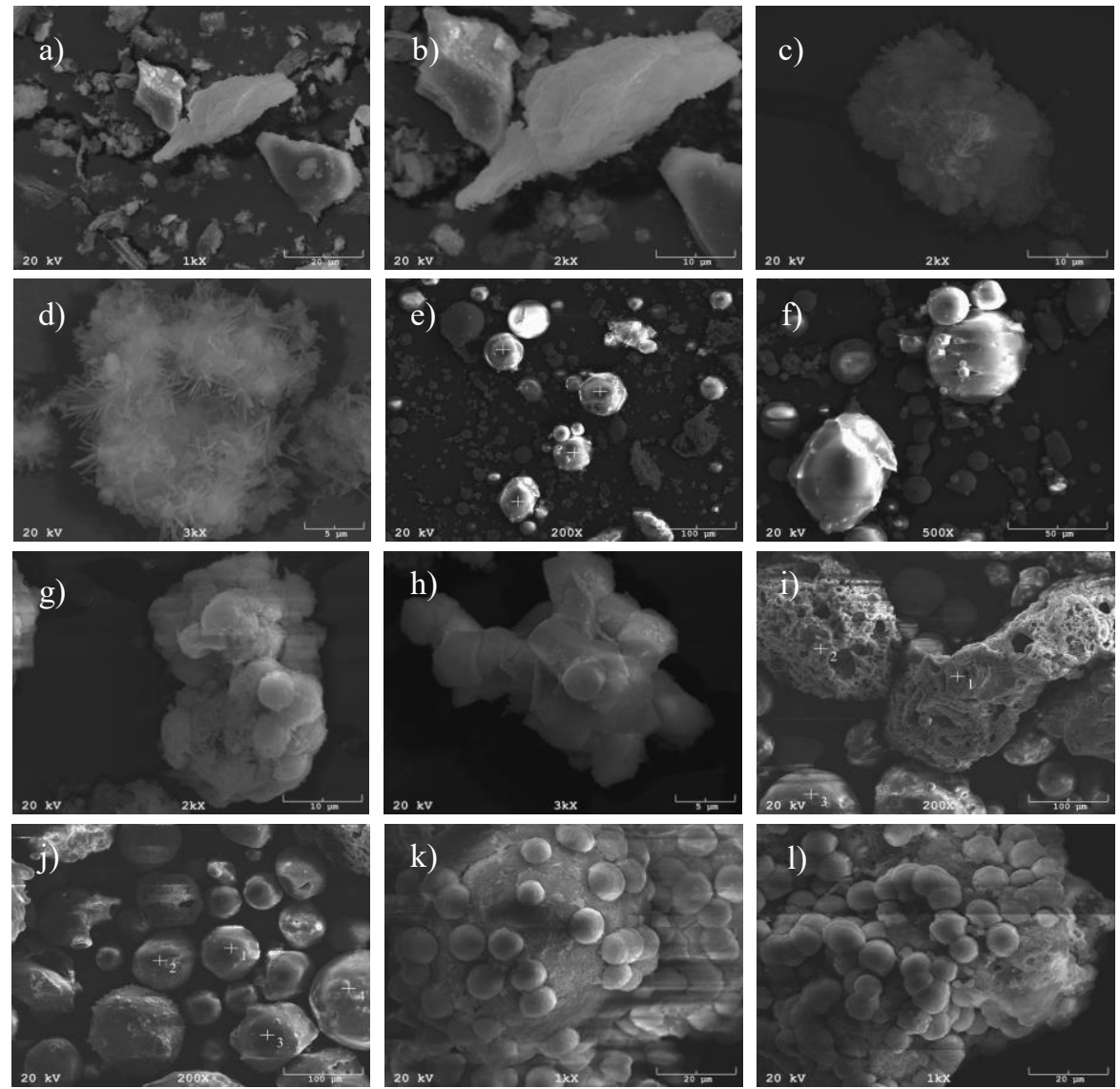

Fig. 4. Morphology of the samples: AA.0.1 (a, b); AA.0.1A (c, d); AA.0.3 (e, f); AA.0.3A (g, h); AA.0.4 (i, j); AA.0.4A (k, l). 
Textural parameters for syntheses product were presented in the Table 2.

Table 2. Textural testing results for samples: AA.0.1A; AA.0.3A; AA.0.4A.

\begin{tabular}{|c|c|c|c|c|}
\hline Sample & S & $\begin{array}{c}\mathbf{V}_{\text {BET }}\left[\mathbf{m}^{2} / \mathbf{g}\right] \\
{\left[\mathbf{c m}^{\mathbf{0}} / \mathbf{g}\right]}\end{array}$ & $\begin{array}{c}\mathbf{V}^{\mathbf{D R}}{ }_{\text {mik }} \\
{\left[\mathbf{c m}^{\mathbf{3}} / \mathbf{g}\right]}\end{array}$ & $\begin{array}{c}\mathbf{V}^{\text {BJH }}{ }_{\text {mez }} \\
{\left[\mathbf{c m}^{\mathbf{3}} / \mathbf{g}\right]}\end{array}$ \\
\hline AA.0.1A & 51 & 0.233 & 0.019 & 0.135 \\
\hline AA.0.3A & 123 & 0.139 & 0.047 & 0.076 \\
\hline AA.0.4A & 54 & 0.110 & 0.025 & 0.072 \\
\hline
\end{tabular}

All samples have a type II isotherm with a hysteresis loop of type H3 (Fig. 4). This corresponds to a mesoporous character with the formation of slitshaped pores arising from the stacking of crystal particles.

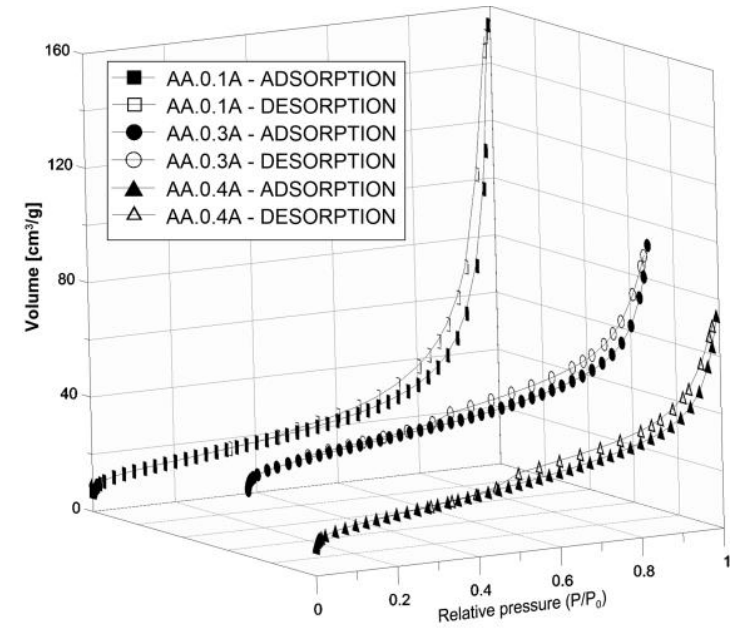

Fig. 4. BET adsorption and desorption isotherms.

The determined values of CEC and AEC for the samples after synthesis are shown in Table 3. Theoretically, the larger the ion exchange capacity of the sample the greater the amount of anions or cations should be retained by ion exchange, i.e. it is easier to desorb. Making a comparison between three samples due to the results of the AEC the best result was obtained for sample AA.0.1A. The determined AEC value was nearly five times higher than the AEC value determined for the clinoptilolite. Samples AA.0.3A and AA.0.4A were characterized by CEC high values, with over twice the CEC value obtained for the natural zeolite (clinoptilolite).

Table 3. The capacity of cation and anion exchange for samples: AA.0.1 A, AA.0.3A, AA.0.4A and clinoptilolite.

\begin{tabular}{|c|c|c|}
\hline Sample & $\begin{array}{c}\text { AEC } \\
{[\mathbf{m e q} / \mathbf{1 0 0 g}]}\end{array}$ & $\begin{array}{c}\text { CEC } \\
{[\mathbf{m e q} / \mathbf{1 0 0 g}]}\end{array}$ \\
\hline AA.0.1A & 84.90 & 18.95 \\
\hline AA.0.3A & 73.34 & 146.07 \\
\hline AA.0.4A & 54.87 & 110.78 \\
\hline Clinoptilolite & 17.38 & 68.73 \\
\hline
\end{tabular}




\section{Conclusions}

The study confirmed that the use of ash from biomass combustion and co-combustion in the synthesis of zeolites makes it possible to obtain synthetic zeolites in excess of natural zeolites, in terms of cation and anion exchange capacity. XRD analyses showed that with the process of synthesis in an autoclave it is possible to obtain zeolites such as sodalite, faujasite, and chabazite. Samples AA.0.3A and AA.0.4A were characterized by CEC high values, with over twice the CEC value obtained for the natural zeolite (clinoptilolite). The largest value of specific surface area was obtained for samples AA.0.3A $\left(123 \mathrm{~m}^{2} / \mathrm{g}\right)$.

\section{Comments}

The results described and the method of synthesizing zeolites are the subject of a patent application in the Polish Patent Office - Application No. P.420936 "A method for the synthesis of zeolites of the ashes resulting from the combustion and co-combustion of biomass", the Applicant - Ekologia Przedsiębiorczość Innowacje spółka z o. 0. The creators of the invention are the authors of this article.

\section{References}

1. G. Berent-Kowalska, J. Kacprowska, I. Moskal, A. Jurgaś, Energia ze źródet odnawialnych w 2015 r. (GUS, 2016)

2. S. Vassilev, D. Baxter, L. Andersen, C. Vassileva,. Fuel 105, 40-76 (2013a)

3. S. Vassilev, D. Baxter, L. Andersen, C. Vassileva, Fuel 105, 19-39 (2013b)

4. A. Jaworek, T. Czech, A. T. Sobczyk, A. Krupa, J. Electrostat. 71,165-175 (2013)

5. R.P. Giron, B. Ruiz, E. Fuente, R.R Gil, I. Suárez-Ruiz, Fuel 114, 71-77 (2013)

6. N.N. Nortey Yeboah, Ch. R. Shearer, S.E. Burns, K. E. Kurtis, Fuel 116, 438-447 (2014)

7. A. Uliasz-Bocheńczyk, A. Pawluk, J. Sierka, Gospod. Surowcami Min. 31, 3, 145-156 (2015)

8. J. Poluszyńska, E. Ślęzak, Prace ICiMB 23, 71-78 (2015)

9. M. Gawlicki, Z. Graur, E. Ślęzak, Prace ICiMB 19, 34-46 (2014)

10. J. Poluszyńska, Prace ICiMB, 13, 49-59 (2013)

11. Ch. W. Purnomo, Ch. Salim, H. Hinode, Micropor. Mesopor. Mat. 162, 6-13 (2012)

12. M.P. Moisés, C.T.P. Silva, J.G. Meneguin, E.M. Girotto, E. Radovanovic, Materials Letters 108, 243-246 (2013)

13. Ch. Santasnachok, W. Kurniawan, Ch. Salim, H. Hinode, JOAAT 1, 2, 75-81(2014)

14. K. L. Chang, W. H. Shih. I\&EC research 37, 71-78 (1998)

15. M. Inada, Y. Eguchi, N. Enomoto, J. Hojo, Fuel 84, 299-304 (2005)

16. A. Derkowski, W. Franus, E. Beran, A. Czimerova, Powder. Technol. 166, 47-54 (2006)

17. C. Belviso, F. Cavalcante, S. Fiore, Waste Manage. 30, 839-847 (2010)

18. W. Franus, M. Wdowin, M. Franus, Environ. Monit. Assess. 186, 5721-5729 (2014)

19. A. Grela, T. Bajda, Inżynieria Ekologiczna 18, 2; 30-38 (2017) 